\title{
The Possible Effects of Need for Uniqueness's Dimensions on Luxury Brands: Case of Iran and UAE
}

\author{
Alireza Miremadi (Corresponding author) \\ Assistant Marketing Professor \& MBA Director \\ Sharif University of Technology - IC, Iran \\ Tel: 98-913-315-2401_E-mail: ar.miremadi@sharif.edu, alireza.miremadi@gmail.com \\ Hiva Fotoohi \\ Sharif University of Technology - IC, Iran \\ Tel: 98-917-713-9851_E-mail: hivaf_65@yahoo.com \\ Farhad Sadeh \\ Sharif University of Technology - IC, Iran \\ Tel: 98-913-314-0173 E-mail: far_sad2@yahoo.com \\ Farhad Tabrizi \\ Sharif University of Technology - IC, Iran
}

Tel: 98-912-301-4352_E-mail: farhad.tabrizi@gmail.com

Kasra Javidigholipourmashhad

Sharif University of Technology - IC, Iran

Tel: 98-912-123-9979Ｅ-mail: Kasra.javi@gmail.com

Received: June 2, 2011 Accepted: July 12, 2011 doi:10.5539/ijms.v3n3p151

\begin{abstract}
The current research aims to explore the possible effects of need for uniqueness's dimensions on fashion luxury brands purchase intentions and to compare Kish and Dubai market in this perspective. The researchers consider three dimensions for uniqueness: creative choice, similarity avoidance and unpopular choice. In addition, the relations between those three dimensions were investigated. Findings indicate that consumers want to express their individuality, and they also want to maintain social norms. This findings support the idea that some consumers prefer expensive and high quality brands that are considered prestigious. This study reveals that there is a relation between creativity choice and unpopular choice among respondents of two markets and the relation between unpopular choice and similarity avoidance, creativity choice and similarity avoidance is only valid among respondents of Iran. The definition of uniqueness for both markets is the same due to order of importance for each constructs in mind of participants in the survey while this definition remain the same between genders and among respondents with different level of education.
\end{abstract}

Keywords: Luxury brand, Fashion, Uniqueness, Purchase intention, Iran, UAE

\section{Introduction}

Today's high-net-worth customers are still shopping but are putting more thought into their purchases. Shoppers today are rethinking their spending. Instead of buying several, lower-priced trendy items like Coach bags, shoppers will spend on a single, longer-lasting luxury goods from Hermes or Chanel, whose handbags run into the thousands of dollars (Sherman, 2009). 
According to Cesare \& Gianluigi (2011) the luxury goods market grew on a worldwide scale during the period from 1995 to 2007. More specifically, the Compound Annual Growth Rate (CAGR) was 11 per cent during the period between 1995 and 1999 (the period of the luxury industry boom), 1 per cent during the three-year period from 2000-2003 (the consolidation of the luxury industry) and 8 per cent between 2004 and 2007 (the expansion of the luxury industry into emerging markets) (Bain \& Company, 2009, as cited in Cesare \& Gianluigi, 2011, p. 1). The two main factors which accelerated development in this sector were principally: the economic growth in Southeast Asia (F. Vigneron, \& Johnson, L. W., 2004), which created "the new rich" and the increase in the use of those products defined as new luxury (Silverstein \& Fiske, 2003). However, it is to be noted that in 2008 the worldwide luxury goods market suffered the effects of the worldwide economic slowdown: taking into consideration the results at current exchange rates of listed companies, total sales volume declined by 2 per cent in comparison with 2007 (Bain \& Company, 2009, as cited in Cesare \& Gianluigi, 2011, p. 2).

This research tries to investigate consumers' intentions and motivations to purchase luxury brands and the effects of cultural differences on them. Kish Island free trade zone in Iran Dubai in the UAE have selected to conducting this research because they are in the same region and both of them are important tourists destination and have some luxury shopping malls. Although most of Kish's tourists are Iranian but Dubai is an international tourism destination. The research has conducted in two luxury shopping malls in Kish and Dubai.

The study aims at discovering of the purchase intention formation for luxury brand by examining of the impact of need for uniqueness attitudes on the luxury brand purchase intentions and motivations among domestic consumers in Kish and multinational consumers in Dubai.

This research can guide marketers in these two area and similar regions to devise suitable marketing strategies based on their customers' culture and preferences.

Luxury brands represent a significant portion of consumer product sales; global sales of luxury brands amounted to 132 billion Euros in 2002 (D'Arpizio, 2004). Louis Vuitton Moet Hennessy (LVMH), the world's leading luxury products group, recorded revenue of $€ 7.8$ billion (about $\$ 11.42$ billion) in its first half of 2009 (LVMH, 2009). However, as a result of the current economic downturn and the recent trend toward cheap trendy fashion that encroach on the luxury market (Sanchanta, 2009), luxury retailers have experienced a sales decrease (Clifford, 2008; Saranow, 2008). Growth in global sales of luxury brands is expected to further decline 7\% as consumers are more reluctant to purchase luxury brands in a poor economy (Sherman, 2009). A clear and actionable understanding of the factors that influence consumers to purchase luxury brands is necessary to inform marketing strategies for global luxury brands.

\section{Literature review}

Luxury is identified in terms of its psychological value, its function as a status symbol and as a highly involved consumption experience that is strongly congruent to a person's self-concept. From a product perspective, luxury brands are frequently defined in terms of their excellent quality, high transaction value, distinctiveness, exclusivity and craftsmanship (Fionda \& Moore, 2009).

Luxury as a concept is defined within the scope of socio-psychology as a result of its connection to a culture, state of being and lifestyle, whether it is personal or collective. When linked to brands, it is characterized by a recognizable style, strong identity, high awareness, and enhanced emotional and symbolic associations. It evokes uniqueness and exclusivity, and is interpreted in products through high quality, controlled distribution and premium pricing (Okonkwo, 2009).

Vigneron and Johnson (2004) differentiate between non-personal- and personal-oriented perceptions. Non-personal-oriented perceptions refer to perceived conspicuousness, uniqueness and quality (as cited in Atwal \& Williams, 2009, p. 2).

Luxury brands have a low ratio of functional utility to price and high ratio of intangible utility to price (Nueno \& Quelch, 1998) and possess diverse dimensions including perceived conspicuous value, perceived unique value, perceived social value, and perceived hedonic value (F. Vigneron \& Johnson, 1999). However, consumers' perceptions of luxury brands are not consistent across market segments, primarily because luxury is a subjective concept (Phau \& Prendergast, 2000) that depends on consumers' perceptions of indulgent value, functional value and price. Therefore, different consumers may perceive different brands to be luxury brands depending on their experiences. One consumer's luxury brand can be another consumer's non-luxury brand. This study defines luxury brands as those brands that provide the consumer with indulgence and are perceived as expensive for the individual. Thus, the brands perceived as luxury brands will differ for different consumers (Bian, 2010). Bian 
(2010) identified Consumers' Purchase Intention Formation for Luxury Brands as needs for uniqueness and self-monitoring.

Considerable research based on Fishbein and Ajzen's (1975), theory of Reasoned Action (TRA) model shows that attitude has a direct impact on intention toward a behavior (Eastlick \& Lotz, 1999; Korzaan, 2003; Penz \& Stottinger, 2005; Szymanski \& Hise, 2000); both self-expression attitude and self-presentation attitude toward luxury brands are expected to predict purchase intentions for luxury brands (as cited in Bian, 2010, p. 8).

Individual needs, such as need for uniqueness and self-monitoring, arouse attitude (KATZ, 1960), and attitude is related to the individual's affective attitude (Kumar, Lee, \& Kim, 2009; Min-Young, Youn-Kyung, Lou, Dee, \& Judith, 2008). Researchers examined need for uniqueness as an individual characteristic that is antecedent to consumers' self-expression attitude toward luxury brands and self-expression in turn impact purchase intention for luxury brands directly and indirectly through their impact on affective attitude (Bian, 2010).

According to Dee \& Eun Young (2007) consumers' need for uniqueness is grounded in Snyder and Fromkin's (1977) uniqueness theory, which manifests itself in the individual's pursuit of material goods to differentiate themselves from others (Tian, Bearden, \& Hunter, 2001).

According to this theory, the need to see oneself as being different from other persons is aroused and competes with other motives in situations that threaten the self-perception of uniqueness (i.e., situations in which individuals see themselves as highly similar to others in their social environment) (Tian, et al., 2001).

Accordingly, consumers' need for uniqueness is defined as the trait of pursuing differentness relative to others through the acquisition, utilization, and disposition of consumer goods for the purpose of developing and enhancing one's self-image and social image (Tian, et al., 2001).

Consumer's need for uniqueness is pointed out in three behavioral dimensions:

(1) Creative choice counter-conformity;

Creative choice counter-conformity reflects that the consumer seeks social differentness from most others but that this consumer makes selections that are likely to be considered good choices by these others (Tian, et al., 2001). In creative choice counter-conformity, consumers purchase goods that express their uniqueness and also are acceptable to others, thus, brand names that can offer some distinguishing attribute (e.g. unique features, exclusivity, and prestige) appeal to consumers who demonstrate this type of consumer behavior (Dee \& Eun Young, 2007).

(2) Unpopular choice counter-conformity;

Unpopular choice counter-conformity refers to the selection or use of products and brands that deviate from group norms and thus risk social disapproval that consumers withstand in order to establish their differentness from others. However, similar to the dimension of creative choice counter-conformity, unpopular counter-conformity may also result in an enhanced self-image and social image (Tian, et al., 2001). These consumers are not concerned about criticism from others; in fact, they tend to make purchase decisions that others might consider to be bizarre (Simonson \& Nowlis, 2000).

(3) Avoidance of similarity;

The final manifestation of consumer's need for uniqueness, avoidance of similarity, products or brands are selected that are not likely to become too popular, but that will distinguish them from others (Dee \& Eun Young, 2007). To avoid similarity with others, consumers may develop a variety of strategies. For instance, they may purchase discontinued styles, shop in vintage stores, or combine apparel in unusual ways. The need for uniqueness can have a significant effect on a consumer's purchase decisions (Simonson \& Nowlis, 2000). Disposition and discontinued product use or purchase to avoid similarity to others occurs because consumers' success in creating distinctive self-images and social images is often short lived. Because consumer choices, particularly creative choices, may establish one's uniqueness, such choices are likely to attract followers who also seek to develop their specialness or share a common link with early adopter groups (Tian, et al., 2001).

Some researchers identify the conditions under which the desire for uniqueness can increase demand among some consumers as the price of a product increases. And also while the desire for uniqueness leads to higher prices and firm profits, a desire for conformity leads to lower prices and profits. Researchers (Amaldoss \& Jain, 2005; Zimmer et al., 1999) have concluded that consumers' with a high need for uniqueness tended to adopt new products or brands more quickly than those with a low need for uniqueness (as cited in Dee \& Eun Young, 2007, p. 3). A review of the relevant literature led us to the following hypotheses. 


\section{Hypotheses Development}

H1: There is a relation between creativity choice and unpopular choice.

$\mathrm{H} 2$ : There is a relation between unpopular choice and similarity avoidance.

H3: There is a relation between creativity choice and similarity avoidance.

H4: There is difference between uniqueness definitions in Dubai and Iran's market.

H5: There is difference between Uniqueness definitions on the base of gender.

H6: There is a new emergence of uniqueness on the base of respondents' educational level of two markets.

\section{Methodology}

\subsection{Measures}

In this study the effect of need for uniqueness on luxury brand choice has been separately evaluated through structured survey including fifteen questions; three main constructs are assumed for need of uniqueness consisted of creative choice, unpopular choice and avoidance of similarity; each construct has been measured by five questions in the survey with seven point Likert scale $(1=$ strongly disagree, $7=$ strongly agree $)$. The surveyed measures for creative choice are composed of uniqueness communication, enhancing distinctive personal image by purchasing unusual brands, self-customization of product or brand, avoiding self-image duplication, individuality expression by the product or brand. The measures for unpopular choice are daring to dress differently, dressing unconventionally, and challenging the prevailing taste of people, breaking customs and rules, continuous of dressing inappropriately. The measures for similarity avoidance are losing interest in using extremely popular brands or products, less using the brands or products spread among general population, disliking customarily purchased products or brands, devaluation of products or brands that regularly purchased by everyone, quit wearing a common style clothing. Location of presenting market, gender, age and educational level are demographic variables inquired in the survey.

Two different versions of questionnaire have been distributed among the participants in this study. The versions differ from the languages. The original language of questionnaire is English, which is distributed among Dubai's sample market, and the language of distributed questionnaire for Iran's sample market is Farsi, which is translated by means of a bilingual student of master of business under supervision of a professor of marketing.

\subsection{Sampling and data collection}

The convenience sampling has been used for this study; sample populations are selected from two different regional markets - Iran and Dubai. Iran's sample market is selected from Kish Island, which contains more tourists and students from other parts of Iran, than local inhabitants, and Dubai sample market is chosen from shopping malls in Dubai. Total number of 272 respondents has answered to survey composed of 138 respondents from Iran and 134 from Dubai. The majority of participants in Dubai were from 20 to 30 years old (53 percent), and second most participants of Dubai market exceeded 32 percent with ages from 31 to 40 . The participants of Dubai were approximately 61 percent female and 39 percent male. The major participants of Iran (about 95 percent) were from 20 to 30 years old. Total participants of Iran are composed of approximately 57 percent male and 43 percent female.

\subsection{Data analysis}

The collected data has been entered and analyzed in SPSS 18. Various statistical tests have been extracted using SPSS. Reliability of the measures for the constructs is evaluated by Cronbach's Alpha. The existence of possible co-relation between three constructs of uniqueness has been examined by bivariate analysis.

Normality test through linear regression has been applied to check the relation between creativity choice and unpopular choice, unpopular choice and similarity avoidance, creativity choice and similarity avoidance.

The definition of uniqueness in two markets is made by different weights assigned to each construct by respondents. The weights are measured by calculating the means of every five questions related to each construct. In this study the means of three constructs arose from different genders and educational levels are compared.

In order to evaluate the different definitions between genders of two markets, T-test is used on the respondents' data for three dimensions. The same procedure is repeated for respondents with various educational levels getting help from Anova test instead of T-test. 


\section{Results and Discussion}

The Cronbach's alpha of measures including creativity choice, unpopular choice, avoidance of similarity and total measures according to total respondents of two markets, is $0.751,0.785,0.873$, and 0.851 respectively. Table 1 reveals the reliability of each measure for each market separately and together.

Table 2 shows the item-construct correlations and reliability coefficients of the dimensions and items. As can be seen from Table 2, the values of the coefficient Alpha for Dubai range from 0.852 to 0.896 for the three constructs above the cut-off value (0.70) recommended by Nunnally and Bernstein (1994). When the whole items in the survey instrument are considered, the coefficient alpha for the Dubai data is 0.886 and that for the Iran data is 0.821 . This means that the overall coefficient alpha scores exceed the 0.70 cut-off value as recommended by Nunnally \& Bernstein (1994). The alpha scores for the Dubai data are 0.852, 0.865 and 0.896 for the creativity choice, unpopular choice and similarity avoidance respectively. The scores for the Iran data on the same three constructs are 0.657, 0.657 and 0.858. All coefficient alphas for Dubai are deemed acceptable at the suggested level (Nunnally \& Bernstein, 1994).

When the corrected item-total correlations in Table 2 are examined carefully, correlations range from 0.511 to 0.865 , all of which are above the suggested 0.32 level (Hair, Money, Samouel, \& Page, 2007). This indicates that the instrument meets the minimum standards of convergent validity. The overall assessment of findings in Table 2 suggests that there is no compelling reason to delete any items from the instrument. Table 2 also shows the resulting mean scores of each measure.

Frequency analysis (descriptive) and multiple-group analysis (multivariate) are carried out (Hair, et al., 2007). Table 2 shows the demographic breakdown of the respondents.

According to Table 3, the majority of the Iran's respondents (55.1 per cent) were male, while the majority of Dubai's (59.7 per cent) were female. The overwhelming majority was between the ages of 20 and 30 (93.5 per cent for Iran; 53.0 per cent for Dubai). The level of education for majority of respondents from Dubai is associated to bachelor degree (41.0 percent) while in Iran this majority is divided between bachelor and master degree ( 42.0 and 42.8 percent respectively).

In order to understand the difference between uniqueness in mind of respondents of each market, composite scores for each construct are calculated by averaging the scores representing it (Table 4). A careful analysis of Table 4 shows the moderate level of standard deviation indicates that respondents were consistent in their answers but nevertheless still indicates enough divergence (Tabachnick \& Fidell, 2007). The mean scores of constructs are calculated for comparing the level of importance regarding the definition of uniqueness in mind of respondents.

\section{Hypothesis testing}

\section{Hypothesis}

H1: There is a relation between creativity choice and unpopular choice.

$\mathrm{H} 2$ : There is a relation between unpopular choice and similarity avoidance.

H3: There is a relation between creativity choice and similarity avoidance.

H4: There is difference between uniqueness definitions in Dubai and Iran's market.

H5: There is difference between Uniqueness definitions on the base of gender.

H6: There is a new emergence of uniqueness on the base of respondents' educational level of two markets.

Hypothesis 1. It is tested whether there is a relation between creative choice and unpopular choice. Correlation between creative choices measures are checked by bivariate test, the significant score calculated for each measure is zero which confirms the correlation inside the measures this test also has been applied for unpopular choice measure which shows the correlation. Normality test has been conducted and standard deviation for Dubai and Iran market is 0.98 so the normal distribution has been approved. The regression test shows the relation between creative choice and unpopular choice measures in two markets, because there is at least one measure with significant score lower than 0.05 . This hypothesis is accepted.

Hypothesis 2. It seeks to find the relation between unpopular choice and similarity avoidance. Correlation between unpopular avoidance has been confirmed before; the same test has been employed for similarity avoidance that confirms the correlation inside similarity avoidance measures. The distributions for both unpopular choice and similarity avoidance constructs are normal with standard deviation 0.98 for both markets. 
The regression test of two constructs for Dubai market has no significant score below 0.05 , which shows no relation between unpopular choice and similarity avoidance in Dubai market, $\mathrm{H} 2$ is rejected. This fact for Iran market is not true; the regression test for Iran has significant score lower than 0.05 so $\mathrm{H} 2$ is approved for Iran.

Hypothesis 3. It examines the existence of relation between similarity avoidance and creative choice. Bivariate test has proven the correlation inside the creativity choice measures, the same test has been employed for the similarity avoidance measures and figures imply every measure exceeds the significant level. The distributions of these constructs for both markets are normal with standard deviation 0.98 . The regression test for Dubai shows no significant score below 0.05 ; so $\mathrm{H} 3$ is rejected while there are three significant measure scores out of five lower than 0.05 , which accepts H3 for Iran.

Hypothesis 4. It determines the different definitions of uniqueness for each market - Iran and Dubai. In order to define the uniqueness, the means of constructs for each market has been compared. The means for creative choice, similarity avoidance and unpopular choice for Iran are 4.4464, 4.1029 and 2.6275 respectively (Table 4); also the means of these three dimensions for Dubai are 4.3343, 3.9900 and 3.1183 respectively (Table 4). This order shows the definitions of respondents for uniqueness in two markets are similar with different weights so $\mathrm{H} 4$ is rejected. According to findings of this study the important constructs for uniqueness in both markets are creative choice, similarity avoidance and unpopular choice respectively.

Hypothesis 5. It follows to determine the difference of definitions for uniqueness on the basis of gender for two markets. The means of each construct are compared using independent sample t-test. According to table 5 and table 6 the order of important constructs for both genders in two markets are similar with different weights, so $\mathrm{H} 5$ is rejected.

Table 5 and Table 6 similarly show the average mean of constructs for each market distinguished by genders.

Hypothesis 6. It seeks to reach the emergence of definition for uniqueness based on education levels of respondents using Anova test. Three average means of dimensions are compared for Iran and Dubai. If the calculated significant score is higher than 0.05 there is no meaningful difference between respondents' views toward definition of uniqueness with different educational level. According to Table 7 significant scores of creative choice, unpopular choice and similarity avoidance for Dubai are $0.009,0.085$ and 0.339 respectively and those for Iran market are 0.419, 0.477 and 0.220. Among three dimensions for Dubai market, creative choice is below 0.05 that implies there is meaningful difference for definition of uniqueness regarding creative choice between education groups in Dubai.

To deeply examine the different views of respondents in Dubai for creative choice, Post Hoc test is applied using Tukey option. The results are illustrated in Table 8.

The average means for different education levels of Dubai market are 3.2000, 3.6588, 4.0000, 4.1793, 4.6400 and 4.7817 for $\mathrm{PhD}$, Non-degree, Master degree, high school diploma, associate degree and bachelor degree respectively. According to table 8 there is no effective difference for creative choice among respondents of different education level in Dubai. Consequently H6 in rejected that there is no new emergence of uniqueness on the base of respondents' educational level of two markets.

\section{Conclusion}

This study examined relationship among dimension of consumers' need for uniqueness by focusing on Iran and Dubai market. The uniqueness in both markets is defined in a same order with respect to three dimensions. The dimensions creative choice, similarity avoidance and unpopular choice are respectively important for respondents of both markets, these consumers want to express their individuality, and they also want to maintain social norms. This findings support the idea that some consumers prefer expensive and high quality brands that are considered prestigious (Amaldoss \& Jain, 2005). This study reveals that there is a relation between creativity choice and unpopular choice among respondents of two markets; because there is at least one measure with significant score lower than 0.05 in the regression test between these two measures in two markets. There is relation between unpopular choice and similarity avoidance in minds of Iranian respondents which is resulted from regression test between unpopular choice and similarity avoidance measures and the relation between creativity choice and similarity avoidance is valid through regression test between creativity choice and similarity avoidance measures, both regression tests show the existence of at least one measure with significant score lower than 0.05 . The definition of uniqueness for both markets is the same due to order of importance for each constructs in mind of participants in the survey while this definition remain the same between genders and among respondents with different level of education. The buying habit of two Iran and UAE markets toward needs for uniqueness for luxury brands derived from creative choice, unpopular choice and similarity avoidance 
measures is approximately similar so the unique techniques of marketing may be applied in these markets sticking in mind some discrepancies of existence or non-existence of relations between mutual measures while comparing two markets.

\subsection{Limitation of research}

In sampling the Iran's market, most respondents are youths from 20 to 30 years old because other age groups rarely show interest to fill the survey for luxury brands. The result may not be precise for other geographical areas in Iran.

\section{References}

Amaldoss, W., \& Jain, S. (2005). Pricing of conspicuous goods: A competitive analysis of social effects. Journal of Marketing Research, 42(1), 30-42.

Atwal, G., \& Williams, A. (2009). Luxury brand marketing - The experience is everything! J Brand Manag, 16(5-6), 338-346.

Bian, Q. (2010). Examining U. S. and Chinese Students' Purchase Intention Formation for Luxury Brands. Auburn University, Auburn

Cesare, A., \& Gianluigi, G. (2011). Determinants of purchasing intention for fashion luxury goods in the Italian market: A laddering approach. Journal of Fashion Marketing and Management, 15(1), 123-136. doi:10.1108/13612021111112386, http://dx.doi.org/10.1108/13612021111112386

D'Arpizio, C. (2004). Luxury Goes Local. [Online] Available: http://www.bain.com/bainweb/publications/publications_detail.asp?id=14359\&menu_url=publications_results.as p (May 21,2011)

Dee, K. K., \& Eun Young, K. (2007). Japanese consumers' need for uniqueness: Effects on brand perceptions and purchase intention. Journal of Fashion Marketing and Management, 11(2), 270-280. doi:10.1108/13612020710751428, http://dx.doi.org/10.1108/13612020710751428

Fionda, A. M., \& Moore, C. M. (2009). The anatomy of the luxury fashion brand. J Brand Manag, 16(5-6), 347-363.

Fishbein, M., \& Ajzen, I. (1975). Belief, attitude, intention, and behavior: an introduction to theory and research. Addison-Wesley Pub. Co.

Hair, J. F. J., Money, A. H., Samouel, P., \& Page, M. (2007). Research methods for business. John Wiley \& Sons, Limited.

KATZ, D. (1960). THE FUNCTIONAL APPROACH TO THE STUDY OF ATTITUDES. Public Opinion Quarterly, 24(2), 163-204.

Kumar, A., Lee, H. J., \& Kim, Y. K. (2009). Indian consumers' purchase intention toward a United States versus local brand. [Proceedings Paper]. Journal of Business Research, 62(5), 521-527.

Min-Young, L., Youn-Kyung, K., Lou, P., Dee, K., \& Judith, F. (2008). Factors affecting Mexican college students' purchase intention toward a US apparel brand. Journal of Fashion Marketing and Management, 12(3), 294-307. doi:10.1108/13612020810889263, http://dx.doi.org/10.1108/13612020810889263

Nueno, J. L., \& Quelch, J. A. (1998). The Mass Marketing of Luxury. Business Horizons, 41(6), 61-68.

Nunnally, J. C., \& Bernstein, I. H. (1994). Psychometric theory. McGraw-Hill.

Okonkwo, U. (2009). The luxury brand strategy challenge. J Brand Manag, 16(5-6), 287-289.

Phau, I., \& Prendergast, G. (2000). Consuming luxury brands: The relevance of the Rarity Principle. The Journal of Brand Management, 8, 122-138.

Sherman, L. (2009). How the Luxury Consumer will Spend in 2009. [Online] Available: http://www.forbes.com/2009/01/13/luxury-spending-rules-forbeslife-cx_ls_0113style.html (May 15,2011)

Silverstein, M. J., \& Fiske, N. (2003). Luxury for the masses. Harvard Business Review, 81(4), 48.

Simonson, I., \& Nowlis, S. M. (2000). The role of explanations and need for uniqueness in consumer decision making: Unconventional choices based on reasons. Journal of Consumer Research, 27(1), 49-68.

Snyder, C. R., \& Fromkin, H. L. (1977). Abnormality as a Positive Characteristic: The Development and Validation of a Scale Measuring Need for Uniqueness. Journal of Abnormal Psychology, 86, 518-527. 
Tabachnick, B. G., \& Fidell, L. S. (2007). Using multivariate statistics. Pearson/Allyn \& Bacon.

Tian, Kelly, T., Bearden, William, O., \& Hunter, Gary, L. (2001). Consumers' Need for Uniqueness: Scale Development and Validation. The Journal of Consumer Research, 28(1), 50-66.

Vigneron, F., \& Johnson, L. W. (2004). Measuring perceptions of brand luxury. The Journal of Brand Management, 11, 484-506.

Vigneron, F., \& Johnson, L. W. (1999). A Review and a Conceptual Framework of Prestige-Seeking Consumer Behavior. Academy of Marketing Science Review, 1999(1).

Table 1. Reliability test for measures of constructs

\begin{tabular}{|l|l|l|l|}
\hline \multirow{2}{*}{ Measures } & \multicolumn{2}{|l|}{ Cronbach's alpha } \\
\cline { 2 - 4 } & Iran & Dubai & Total \\
\hline Creativity choice & 0.657 & 0.852 & 0.751 \\
Unpopular choice & 0.657 & 0.865 & 0.785 \\
Similarity avoidance & 0.858 & 0.896 & 0.873 \\
Total & 0.821 & 0.886 & 0.851 \\
\hline
\end{tabular}

Table 2. Scale items, reliabilities, corrected item-total correlations and mean scores

\begin{tabular}{|c|c|c|c|c|}
\hline & \multicolumn{2}{|c|}{ Iran } & \multicolumn{2}{|c|}{ Dubai } \\
\hline Scale items & Corr & Mean & Corr & Mean \\
\hline Creativity choice & \multicolumn{2}{|c|}{$\alpha=0.657$} & \multicolumn{2}{|c|}{$\alpha=0.852$} \\
\hline $\begin{array}{l}\text { Often when buying apparel and accessories an important } \\
\text { goal is to find the luxury brand that communicates my } \\
\text { uniqueness. }\end{array}$ & 0.684 & 4.6957 & 0.675 & 4.0299 \\
\hline $\begin{array}{l}\text { I have sometimes purchase unusual brands or products to } \\
\text { create a more distinctive personal image. }\end{array}$ & 0.528 & 3.2754 & 0.780 & 4.2761 \\
\hline $\begin{array}{l}\text { I look for one-of-a-kind products or brands so that I create } \\
\text { a style that is all my own. }\end{array}$ & 0.684 & 4.8551 & 0.837 & 4.3881 \\
\hline $\begin{array}{l}\text { I often combine possessions in such a way that I create a } \\
\text { personal image for myself that can't be duplicated. }\end{array}$ & 0.724 & 4.5362 & 0.834 & 4.2836 \\
\hline $\begin{array}{l}\text { The products and brands that I like best are the ones that } \\
\text { express my individuality. }\end{array}$ & 0.620 & 4.8696 & 0.833 & 4.6917 \\
\hline Unpopular choice & \multicolumn{2}{|c|}{$\alpha=0.657$} & \multicolumn{2}{|c|}{$\alpha=0.865$} \\
\hline $\begin{array}{l}\text { When dressing, I have sometimes dared to be different in } \\
\text { ways that others are likely to disapprove. }\end{array}$ & 0.674 & 2.5797 & 0.763 & 3.6515 \\
\hline $\begin{array}{l}\text { I often dress unconventionally even when it's likely to } \\
\text { offend others. }\end{array}$ & 0.795 & 2.2899 & 0.795 & 2.8358 \\
\hline $\begin{array}{l}\text { I enjoy challenging the prevailing taste of people I know } \\
\text { by buying something they wouldn't seem to accept. }\end{array}$ & 0.743 & 2.9348 & 0.848 & 3.3284 \\
\hline $\begin{array}{l}\text { When it comes to the products I buy and the situations in } \\
\text { which I use them, I have often broken customs and rules. }\end{array}$ & 0.511 & 2.2971 & 0.828 & 2.9398 \\
\hline $\begin{array}{l}\text { If someone hinted that I had been dressing inappropriately } \\
\text { for a social situation, I would continue dressing in the } \\
\text { same manner. }\end{array}$ & 0.563 & 3.0362 & 0.787 & 2.8195 \\
\hline Similarity avoidance & \multicolumn{2}{|c|}{$\alpha=0.858$} & \multicolumn{2}{|c|}{$\alpha=0.896$} \\
\hline $\begin{array}{l}\text { When products or brands I like become extremely popular, } \\
\text { I lose interest in them. }\end{array}$ & 0.700 & 3.4710 & 0.791 & 3.7820 \\
\hline $\begin{array}{l}\text { When a product I own becomes popular among the general } \\
\text { population, I begin using it less. }\end{array}$ & 0.807 & 4.5145 & 0.828 & 3.9242 \\
\hline $\begin{array}{l}\text { I dislike brands or products that are customarily purchased } \\
\text { by everyone. }\end{array}$ & 0.831 & 4.2319 & 0.865 & 4.1194 \\
\hline $\begin{array}{l}\text { Products don't seem to hold much value for me when they } \\
\text { are purchase regularly by everyone. }\end{array}$ & 0.816 & 4.1304 & 0.856 & 4.0970 \\
\hline $\begin{array}{l}\text { When a style of clothing I own becomes too common, I } \\
\text { usually quit wearing it. }\end{array}$ & 0.836 & 4.1667 & 0.849 & 4.0224 \\
\hline
\end{tabular}


Table 3. Demographic breakdown of the sample

\begin{tabular}{|c|c|c|c|c|c|}
\hline & & \multicolumn{2}{|c|}{$\operatorname{Iran}(\mathrm{n}=138)$} & \multicolumn{2}{|c|}{ Dubai $(n=134)$} \\
\hline & & $\mathrm{F}$ & $\%$ & $\mathrm{~F}$ & $\%$ \\
\hline \multicolumn{6}{|c|}{ Gender } \\
\hline \multirow{3}{*}{ Valid } & Male & 76 & 55.1 & 51 & 38.1 \\
\hline & Female & 58 & 42.0 & 80 & 59.7 \\
\hline & Total & 134 & 97.1 & 131 & 97.8 \\
\hline \multicolumn{2}{|c|}{ Missing system } & 4 & 2.9 & 2 & 2.2 \\
\hline \multicolumn{6}{|c|}{ Age } \\
\hline \multirow{6}{*}{ Valid } & Under 20 & 6 & 4.3 & 8 & 6.0 \\
\hline & $20-30$ & 129 & 93.5 & 71 & 53.0 \\
\hline & $31-40$ & 1 & 0.7 & 44 & 32.8 \\
\hline & $41-50$ & 0 & & 8 & 6.0 \\
\hline & Above 50 & 0 & & 3 & 2.2 \\
\hline & Total & 136 & 98.6 & 134 & 100 \\
\hline \multicolumn{2}{|c|}{ Missing system } & 2 & 1.4 & & \\
\hline \multicolumn{6}{|c|}{ Education } \\
\hline \multirow{7}{*}{ Valid } & Non degree & 1 & 0.7 & 15 & 11.2 \\
\hline & High school diploma & 12 & 8.7 & 29 & 21.6 \\
\hline & Associate degree & 6 & 4.3 & 10 & 7.5 \\
\hline & Bachelor degree & 58 & 42.0 & 55 & 41 \\
\hline & Master degree & 59 & 42.8 & 19 & 14 \\
\hline & $\mathrm{PhD}$ & 0 & 0 & 1 & 0.7 \\
\hline & Total & 136 & 98.6 & 129 & 96.3 \\
\hline \multicolumn{2}{|c|}{ Missing system } & 2 & 1.4 & 5 & 3.7 \\
\hline
\end{tabular}

Table 4. Mean score differences of dimensions - Iran versus Dubai

\begin{tabular}{|l|l|l|l|l|}
\hline \multirow{2}{*}{ Dimensions } & \multicolumn{2}{|c|}{ Iran } & \multicolumn{2}{c|}{ Dubai } \\
\cline { 2 - 5 } & Mean & SD & Mean & SD \\
\hline Creative choice & 4.4464 & 1.19812 & 4.3343 & 1.33856 \\
\hline Unpopular choice & 2.6275 & 1.04977 & 3.1183 & 1.35607 \\
\hline Similarity avoidance & 4.1029 & 1.63023 & 3.9900 & 1.52842 \\
\hline
\end{tabular}

Table 5. Mean score differences of dimensions for Iran - Male versus Female

\begin{tabular}{|l|l|l|l|l|}
\hline \multirow{2}{*}{ Dimensions } & \multicolumn{2}{|c|}{ Male } & \multicolumn{2}{c|}{ Female } \\
\cline { 2 - 5 } & Mean & SD & Mean & SD \\
\hline Creative choice & 4.0342 & 1.23089 & 4.8966 & 0.91785 \\
\hline Unpopular choice & 2.5632 & 1.01125 & 2.6069 & 0.96097 \\
\hline Similarity avoidance & 3.9816 & 1.60538 & 4.1552 & 1.64030 \\
\hline
\end{tabular}

Table 6. Mean score differences of dimensions for Dubai - Male versus Female

\begin{tabular}{|l|l|l|l|l|}
\hline \multirow{2}{*}{ Dimensions } & \multicolumn{2}{|c|}{ Male } & \multicolumn{2}{c|}{ Female } \\
\cline { 2 - 5 } & Mean & SD & Mean & SD \\
\hline Creative choice & 4.1373 & 1.35230 & 4.4775 & 1.31726 \\
\hline Unpopular choice & 3.2480 & 1.35687 & 3.0725 & 1.37094 \\
\hline Similarity avoidance & 3.9503 & 1.49737 & 4.0000 & 1.53210 \\
\hline
\end{tabular}


Table 7. Comparison of mean scores of measures with Anova test

\begin{tabular}{|l|l|l|}
\hline \multirow{2}{*}{ Dimension } & \multicolumn{2}{|c|}{ Significant } \\
\cline { 2 - 3 } & Iran & Dubai \\
\hline Creative choice & 0.419 & 0.009 \\
\hline Unpopular choice & 0.477 & 0.085 \\
\hline Similarity avoidance & 0.220 & 0.339 \\
\hline
\end{tabular}

Table 8. Applied post hoc method in Anova test

\begin{tabular}{|l|l|l|}
\hline Education Level & N & Subset for alpha $=0.05$ \\
\hline $\mathrm{PhD}$ & 3 & 3.2000 \\
\hline Non Degree & 17 & 3.6588 \\
\hline Master Degree & 19 & 4.0000 \\
\hline High school Diploma & 29 & 4.1793 \\
\hline Associate Degree & 10 & 4.6400 \\
\hline Bachelor Degree & 55 & 4.7817 \\
\hline Sig. & & 0.069 \\
\hline
\end{tabular}

